\title{
Long-term follow up of patients with dilated heart muscle disease treated with human leucocytic interferon alpha or thymic hormones Initial results
}

Milutin Mirić, Jovan Vasiljević, Milovan Bojić, Zoran Popović, Nenad Keserović, Milan Pešić

\section{Abstract}

Objective-To determine whether giving interferon- $\alpha$ or thymomodulin in addition to conventional treatment improves cardiac function in patients with idiopathic myocarditis and idiopathic dilated cardiomyopathy.

Design-Single-centre, randomised, open label, parallel group comparison of conventional treatment plus interferon- $\alpha$, conventional treatment plus thymomodulin, and conventional treatment alone.

Patients-38 patients aged 19-54 years (23 men) with biopsy-proven myocarditis or dilated cardiomyopathy. 12 were treated with conventional treatment alone, 13 were treated with interferon- $\alpha$ and conventional treatment, and 13 with thymomodulin and conventional treatment.

Setting-Tertiary cardiac referral centre. Main outcome measures-Clinical evaluation, echocardiography, and Holter monitoring at baseline, 6 months, and 1 and 2 years. Radionuclide ventriculography at rest and during exercise after 2 years. Endomyocardial biopsy at baseline and after a year if the initial diagnosis was myocarditis.

Results-Left ventricular ejection fraction was improved in $21(81 \%)$ of 26 patients after interferon- $\alpha$ or thymomodulin administration and in $8(66 \%)$ of 12 conventionally treated patients $(P<0.05)$ at 2 year follow up. The maximum exercise time was significantly longer at 2year follow up in patients treated with immunomodulators (mean (SEM) 5.1 $(0 \cdot 6)$ minutes for interferon- $\alpha$ and 5.0 $(0.4)$ minutes for thymomodulin) than in conventionally treated patients $(3.3(0.4)$ minutes). Left ventricular ejection fraction during exercise (assessed by radionuclide ventriculography) improved in 9 of 12 patients treated with interferon- $\alpha, 10$ of 12 patients treated with thymomodulin, and 3 of 9 conventionally treated patients at 2 year follow up. The electrocardiogram was normal in $21(88 \%)$ of 24 patients after interferon- $\alpha$ or thymomodulin treatment and $2(22 \%)$ of 9 conventionally treated patients. At 2 year follow up, $19(73 \%)$ of 26 patients treated with immunomodulators and $4(25 \%)$ of 12 conventionally treated patients had improved their functional class.

Conclusions-The results suggest that treatment of idiopathic myocarditis and/or idiopathic dilated cardiomyopathy with interferon- $\alpha$ or thymomodulin induces an earlier and significantly superior clinical improvement than conventional treatment alone.

(Heart 1996;75:596-601)

Keywords: idiopathic myocarditis; idiopathic dilated cardiomyopathy; interferon- $\alpha$; thymic hormones

Enteroviruses and other viruses or viral sequences have been found in the cardiac tissues of patients with idiopathic myocarditis and idiopathic dilated cardiomyopathy. ${ }^{1-3}$ Possibly cardiotropic viruses cause not only a symptomatic or asymptomatic initial infection but also persist in the myocardium of some patients. ${ }^{4-6}$ During persistent infections there is frequently a reduction in the virally encoded surface glycoproteins expressed on the outer membrane of infected cells. ${ }^{78}$ This reduction in viral proteins on infected cells provides an advantage for the persisting virus, because such cells are less vulnerable to immunological attack by humoral or cell-mediated effector mechanisms. At the same time, such infected cells fail to activate lymphocytes with natural killer cell activity. ${ }^{9} \mathrm{~A}$ deficiency in host defenses, such as the interferon system, might contribute to the development of persistent infections. If viruses do cause idiopathic myocarditis and some cases of idiopathic dilated cardiomyopathy, treatment with interferon or its inducers may be appropriate, either because of its direct action on the target cell or indirect effects (activation of cycotoxicity, modulation of immune responses, and interaction with other mediators of immune response). This was the rationale for our clinical trial of interferon- $\alpha$ or thymic hormones in patients with dilated heart muscle disease. We chose interferon- $\alpha$ because it is highly diffusible and easily reaches distant organs after subcutaneous injection and thymic hormones because they induce a rise in the concentration of endogenous interferon and stimulate natural killer and $T$ cell activities. ${ }^{10}$ We performed a serial evaluation of clinical data over a two year period to document the possible influence of immunomodulatory treatment on the natural course of idiopathic myocarditis and idiopathic dilated cardiomyopathy, because these diagnoses could represent two forms of the same disease. ${ }^{11}$ 


\section{Patients and methods}

We studied 38 patients ( 15 women and 23 men) in whom the diagnosis of idiopathic myocarditis or idiopathic dilated cardiomyopathy had been confirmed by biopsy and who had a left ventricular ejection fraction (LVEF) of $<45 \%$ at angiography. Those with postpartum and familial cardiomyopathy, giant-cell myocarditis, and all forms of secondary myocarditis were excluded, as were patients with ischaemia, valvar or congenital heart disease, severe hypertension, alcoholism, pregnancy or postpartum, and autoimmune or other life-threatening disease. Initial evaluation included clinical symptoms, immunological tests, chest $x$ rays, electrocardiogram, cross sectional echocardiographic examination, right and left heart haemodynamic studies, and right ventricular endomyocardial biopsy. Three or four myocardial tissue samples were taken and studied by light microscopy to establish the histological diagnosis, according to the Dallas criteria ${ }^{12}$ (femoral approach, King's bioptome). Molecular biological techniques including in situ hybridisation and polymerase chain amplification were not available at the time of the study.

\section{IMMUNOLOGICAL INVESTIGATIONS}

Blood was taken for measurement of virus neutralising antibody titres, humoral, and cellular studies. Humoral studies included: (a) a search for circulating antibodies against cardiac muscle, skeletal muscle, smooth muscle, and parietal cells as well as those against components of the nuclei and the mitochondria (immunofluorescence assay) $)^{13}$; (b) analysis of sera for IgM, IgG, IgA, IgD, and IgE, (laser nephelometry) ${ }^{14}$; and (c) detection of circulating immune complexes (laser nephelometry with LN Latex CIC Reagent, Behring). ${ }^{15}$ Among cellular studies, phenotyping of peripheral blood mononuclear cells and natural killer cell assay $\left({ }^{51} \mathrm{Cr}\right.$ release assay) ${ }^{16}$ were performed to define the patient's lymphocyte subpopulations and non-specific cell-killing ability. For phenotyping of peripheral blood mononuclear cells we used monoclonal antibodies (OKT3, OKT4, OKT8 (Ortho Diagnostics, Raritan, NJ) and Leu-7 (BectonDickinson, Mountain View, CA)), fluorescein isothiocyanate staining, and flow cytometric enumeration. ${ }^{17-19}$ Immunological studies were repeated weekly and monthly during the first six months of follow up.

The study design was a prospective, randomised, open label comparison of conventional treatment with conventional treatment plus immunomodulation with interferon- $\alpha$ or thymic hormones. After approval by the Institution Review Board and after consent forms were signed, the patients were randomly assigned to three treatment groups: (1) 12 patients received conventional treatment for congestive heart failure, (2) 13 patients received conventional treatment plus interferon- $\alpha$; and (3) 13 patients received conventional treatment plus thymic hormone. Treatment lasted for three months. For the next three months all patients received con- ventional treatment alone. The criteria for administration of conventional treatment were set at the beginning of the study. A specific stepwise conventional regimen, with identical doses in all treatment groups, was given by the same physician in the order listed below:

- reduced salt intake (less than $4 \mathrm{~g}$ a day).

- Digoxin (serum concentration of 1-2 $\mathrm{mg} / \mathrm{ml}$ ).

- Frusemide (40-160 mg/day).

- Captopril ( $25 \mathrm{mg}$ three times a day).

- Metolazone (2.5-5 mg/day).

- Warfarin (if LVEF was < $35 \%$ ) to maintain the international normalised ratio for prothrombin time in the range $2 \cdot 5-4 \cdot 0$.

These steps were followed in order as necessary.

Purified leucocytic interferon- $\alpha$ (Torlak, Beograd) was given at 3 million $\mathrm{U} / \mathrm{m}^{2}$ of body surface area subcutaneously three times a week. Thymus-TFX Thymomodulin $(10 \mathrm{mg})$ (Thymoorgan, Pharmazie, Vieneburg, Germany) was given subcutaneously three times a week. Thymus-TFX thymomodulin is a biologically active extract of the thymus gland of calves consisting of polypeptides between 4000 and 6000 daltons.

At six month, one year, and two year follow up we performed clinical evaluation, echocardiographic studies (biplane method for LVEF measurements), chest $x$ rays, and Holter monitoring. At one year, we repeated the right ventricular endomyocardial biopsy if the initial diagnosis was myocarditis. At two years radionuclide ventriculography gated bloodpool technique was performed at rest and during exercise.

\section{STATISTICAL ANALYSIS}

Measurements were mean (SEM). Statistical analysis was performed using analysis of variance for repeated measures (Newman-Keuls multiple comparisons) and analysis of variance by the modified $t$ test (Bonferroni) as appropriate. Results were regarded as significant if $P$ was less than 0.05 .

\section{Results}

Four patients had histological diagnosis of active and 11 patients of borderline myocarditis. Their average age at presentation was $29 \cdot 3$ years (range 19-40 years). Twenty three patients had a histological diagnosis of idiopathic dilated cardiomyopathy (mean age at presentation of 31.7 years (range 19-54 years)).

We found raised virus neutralising antibody titres, usually to Coxsackie B viruses, in 14 patients.

At the start of the study two patients were in New York Heart Association class II, 26 patients were in class III, and 10 in class IV. There was no significant baseline medical difference among the three treatment groups. Left ventricular function assessed by angiography at the beginning of the study was similar (LVEF was $22.7(1 \cdot 2) \%$ in patients treated with interferon- $\alpha, 22$ (14)\% in patients treated with thymomodulin, and $23.9(1 \cdot 1) \%$ in con- 
Figure 1 Natural killer cells as a percentage of peripheral blood mononuclear cells (PBMC) in 38 patients with dilated heart muscle disease during treatment. IFN, interferon$\alpha ; T H$, thymomodulin, $P<0.0001$ (ANOVA for repeated measures,

Newman-Keuls multiple comparisons, error bars $=$ SEM).

Figure 2 Effects of three treatments on natural killer cell activity and

neutralising antibody titres during six month follow up in 38 patients with dilated heart muscle disease.

IFN $=$ Interferon $-\alpha$.
Figure 3 Effects of three treatments on left ventricular ejection fraction (LVEF) in 38 patients with dilated heart muscle disease treated with IFN- $\alpha$ and conventional treatment; thymomodulin and conventional treatment, and conventional therapy alone (mean (SEM), $P<$ 0.0001 ) (ANOVA for repeated measures, Newman-Keuls multiple comparisons).

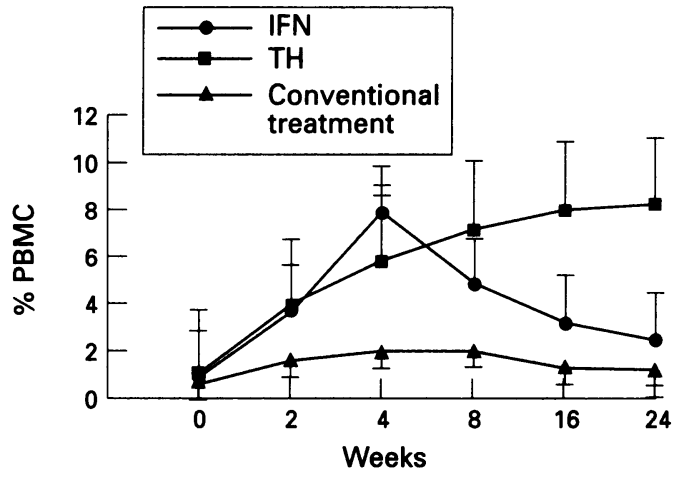

Left ventricular ejection fraction (LVEF) at the beginning of the study and after two year follow up in patients with dilated heart muscle disease according to diagnosis and treatment

\begin{tabular}{llll}
\hline No & Start & No & $2 y$ \\
\hline Idiopathic myocarditis: & & & \\
5 & $23.0(1 \cdot 2)$ & & $31 \cdot 0(2 \cdot 1)$ \\
5 & $23 \cdot 6(1 \cdot 3)$ & & $32 \cdot 8(1 \cdot 4)$ \\
5 & $23.4(1 \cdot 0)$ & & $27 \cdot 6(1 \cdot 4)$ \\
IDC: & & & \\
8 & $22.5(1 \cdot 1)$ & 7 & $29 \cdot 4(2 \cdot 3)$ \\
8 & $21 \cdot 0(1 \cdot 5)$ & 7 & $29 \cdot 1(1 \cdot 6)$ \\
7 & $24 \cdot 1(1 \cdot 2)$ & 4 & $26 \cdot 2(1 \cdot 7)$ \\
\hline
\end{tabular}

ventionally treated patients). Thirty five patients had electrocardiographic abnormalities. Natural killer cells were absent or significantly decreased in all patients, while natural killer cell activity was low in 35 patients.

The relative number of natural killer cells increased significantly after two weeks of treatment in the interferon- $\alpha$ group and returned to the baseline count after six months (fig 1). In contrast to this sharp, short term increase in natural killer cells, we found a progressive, long term increase in the thymomodulin group. A significant increase in natural killer cell activity was seen in the interferon- $\alpha$ and thymomodulin treated patients. This started at two weeks and lasted for months (from 30.6 $(1.4) \%$ to $48.5(1.9) \%$ in the interferon- $\alpha$ group, and from $28.6(1.2) \%$ to $44.7(1.6) \%$ in the thymomodulin group). We did not find a change in natural killer cell activity in conventionally treated patients $(P<0.0001$, analysis of variance for multiple comparisons). Increase in the relative number of natural killer cells and natural killer cell activity was followed by significant decrease in neutralising antibody viral titres in patients treated with immunomodulators (fig 2).

In 10 interferon- $\alpha$ treated and 11 thymomodulin treated patients, resting LVEF assessed by echocardiography improved at six months and showed further improvement at two year follow up (fig 3). Resting LVEF improved in eight conventionally treated patients at two year follow up. This improvement was found in a significantly lower proportion than in patients treated with immunomodulators $(P<0.05$, analysis of
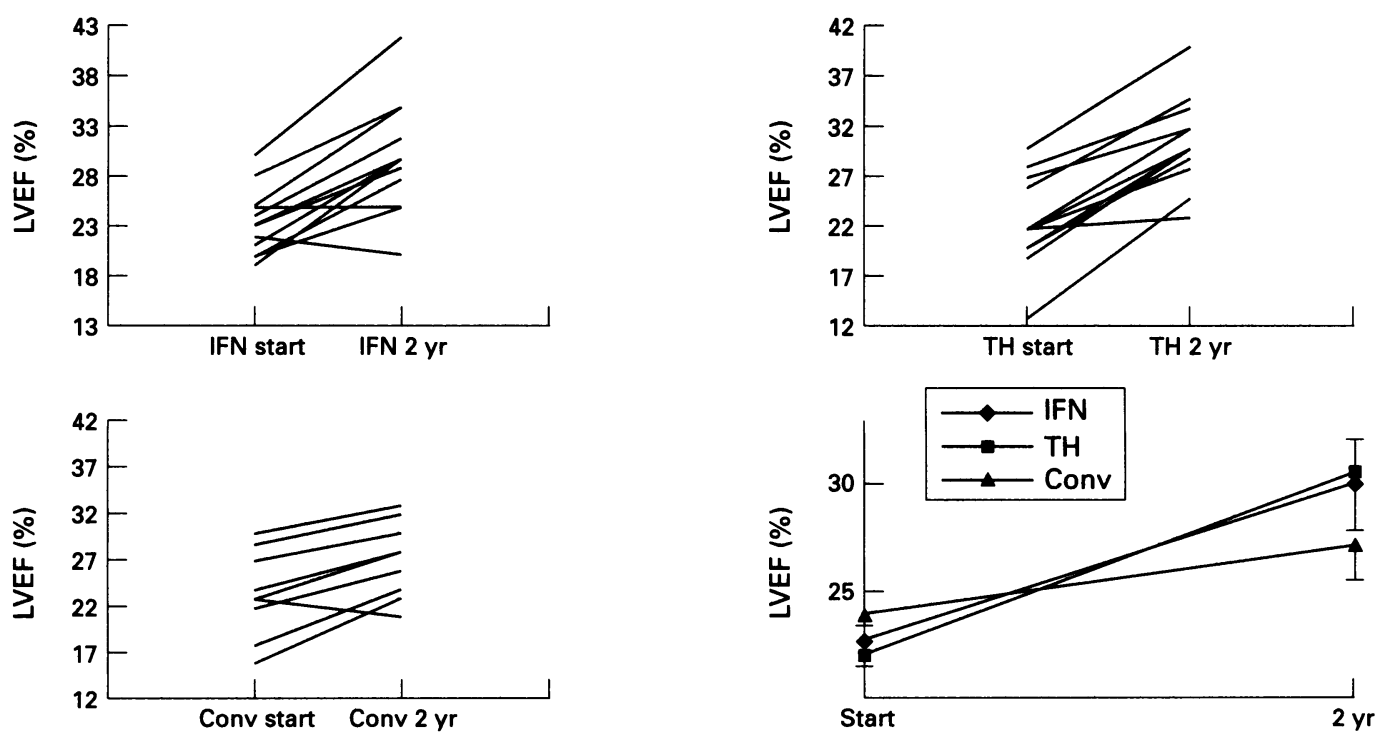
Figure 4 Left ventricular ejection fraction ( $L V E F)$ during exercise in 33 patients at two year follow up during treatment with IFN- $\alpha$ and conventional treatment, thymomodulin and conventional treatment, and conventional treatment alone (mean (SEM), $P<$ 0.0001 ) (ANOVA for repeated measures, Newman-Keuls multiple comparisons).

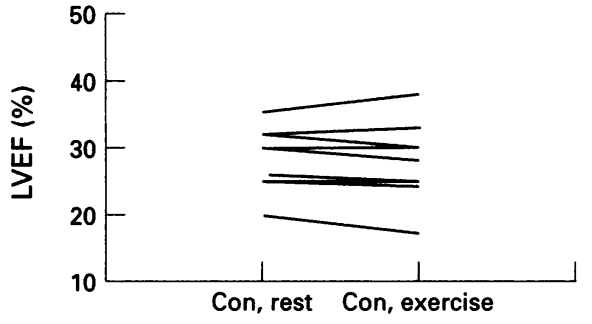

variance for multiple comparisons). The table shows changes in resting LVEF during two year follow up in the treatment groups according to the diagnosis. There were too few patients in each group for these changes to be analysed statistically. At the two year follow up left ventricular ejection fraction was higher at peak exercise than at rest in nine patients treated with interferon- $\alpha$ and 10 with thymomodulin (fig 4). In seven conventionally treated patients, the ejection fraction decreased or failed to increase on exercise, indicating an abnormal haemodynamic response. Maximum exercise time at two year follow up was $5 \cdot 1(0.6)$ minutes in the interferon- $\alpha$ group, $5(0.4)$ minutes in thymomodulin group, and $3.3(0.4)$ minutes in the conventionally treated group $(P<0.01$, analysis of variance, modified $t$ test, Bonferroni).

Biopsy was repeated at one year. In five patients with initial diagnosis of myocarditis who were treated with interferon- $\alpha$ (two active and three borderline) myocarditis had resolved. Of five patients treated with thymomodulin (one active and four borderline myocarditis), one had resolving myocarditis and four had resolved myocarditis. In the conventionally treated group, one patient who initially had active myocarditis had resolving myocarditis, two who initially had borderline myocarditis had resolved myocarditis, and two who initially had borderline myocarditis had a histological diagnosis of dilated cardiomyopathy.

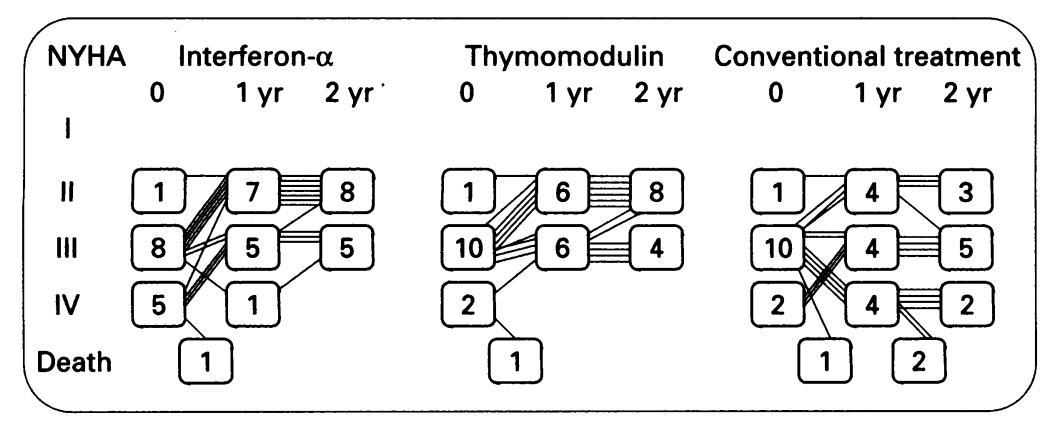

Figure 5 NYHA classification at two year follow up in 38 patients with dilated heart muscle disease.

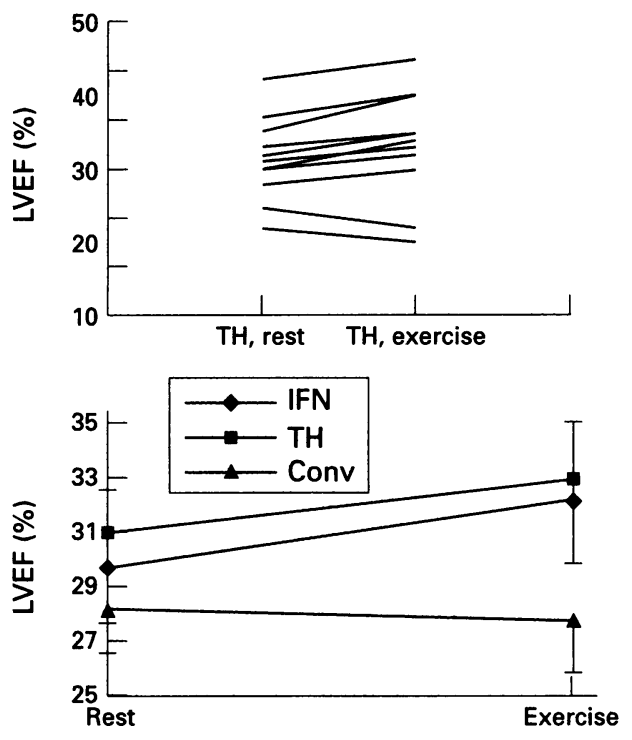

In nine patients treated with interferon- $\alpha$ and six treated with thymomodulin NYHA class had improved at one year (fig 5). At two year follow these patients maintained their improvement. In five conventionally treated patients the functional class had improved at one year, and in one of them it had worsened again at two year follow up.

One interferon- $\alpha$ treated patient with biopsy confirmed idiopathic dilated cardiomyopathy died five months after presentation. It was a sudden death outside hospital. One thymomodulin treated patient died at nine months of an embolic cerebrovascular accident. Three patients in the conventionally treated group died during two year follow up-one suddenly and two from end stage cardiac failure.

\section{Discussion}

Dilated heart muscle disease can be idiopathic (IDC) or secondary to other causes, such as viral myocarditis or viral perimyocarditis. ${ }^{20}$ The criteria for IDC in our study were angiographic evidence of cardiomegaly and reduced ejection fraction $(<45 \%)$; exclusion of coronary artery disease, valvar heart disease, hypertension, and other forms of secondary heart muscle diseases; and histopathological findings of hypertrophy and branching of the myocytes, with diffuse or focal fibrosis. The criteria for idiopathic myocarditis were biopsy confirmed inflammation of the myocardium with infiltrate, focal necrosis, and interstitial oedema with or without fibrosis. Fourteen patients also had significant changes ( $>$ threefold increase) in virus neutralising antibody titres against cardiotropic viruses. RNA and DNA probes for cardiotropic viruses were not available in our study.

Though there are many causes of dilated cardiomyopathy and the aetiology is frequently difficult to determine, it is becoming increasingly apparent that after an acute or subacute episode of viral myocarditis the virus can persist in the cardiac tissues and cause dilated cardiomyopathy. ${ }^{621}$ In human diseases thought to be caused by putative persistent infections, 
there is evidence of diminished interferon production and natural killer activity by lymphocytes. ${ }^{22} 23$

Left ventricular ejection fractions improved in $21(81 \%)$ of 26 patients after interferon- $\alpha$ or thymomodulin administration and to a lesser extent in eight $(66 \%)$ of 12 conventionally treated patients $(P<0.01)$ at six month follow up. Maximum exercise time was significantly longer at two year follow up in patients treated with immunomodulators. Left ventricular reserve, assessed by rest and exercise radionuclide ventriculography was significantly higher in patients treated with interferon- $\alpha$ or thymomodulin. The electrocardiogram was normal in $21(88 \%)$ of 24 patients after interferon- $\alpha$ or thymomodulin treatment and in two (22\%) of nine conventionally treated patients. At two year follow up, $19(73 \%)$ of 26 patients treated with immunomodulators and four (25\%) of 12 conventionally treated patients showed an improvement in functional class.

We found a significant increase in relative number of natural killer cells and enhancement of natural killer cell activity in patients treated with interferon- $\alpha$ or thymomodulin. Both the increase in natural killer cell number and activation occurred quickly with interferon- $\alpha$ and disappeared after four weeks of treatment. Activation was slower with thymomodulin but lasted significantly longer. Patients treated conventionally had no changes in relative number of natural killer cells and natural killer cell activity.

Increased natural killer cell activity is associated with a more effective inflammatory response and less severe initial myocarditis. ${ }^{24}$ The natural killer cell response is mainly responsible for elimination of virus in the early phase of the disease, but when viral infection persists it could also be important in eliminating virus in late phase of the disease. Our findings accord with the suggestion of Mason et $a l^{4}$ that a strong spontaneous immune response could be a beneficial rather than an initiating factor in myocarditis ${ }^{24}$ and also with the concept that stimulation of the immune response by immunomodulators could be of benefit even in idiopathic dilated cardiomyopathy.

Our data strongly suggest treatment of myocarditis and idiopathic dilated cardiomyopathy with interferon- $\alpha$ or thymomodulin, and in our opinion they accord with the conclusions of Mason et al, who do not recommend the routine use of immunosuppressive drugs. Nonetheless, immunohistological findings in some groups of patients indicate that immunosuppressive drugs may be beneficial.

There were minor complications of endomyocardial biopsy in two of the 38 patients before treatment was started and in one (6\%) of the 15 repeat biopsies. Eleven of the 13 patients treated with interferon- $\alpha$ had a 'flulike symptom dominated by fever, a few hours after the start of treatment. The peak temperature tended to decrease with repeated injections and usually disappeared after 10 days of treatment. In two patients it was associated with lassitude and malaise. Cardiovascular and neurological symptoms were not reported. Reversible mild leucothrombocytopenia was seen in six patients. Treatment did not have any significant effect on serum transaminases. Reversible heart dilatation ${ }^{25-27}$ was not seen either.

Four of the 13 patients treated with thymomodulin had a slight, but transient increase in weight. In two women menstrual bleeding was prolonged.

Patients with a left ventricular ejection fraction $<30 \%$ have a poor prognosis and many such patients are on a progressively downhill course and are likely to die within a few years. The poor prognosis of idiopathic heart muscle disease justifies the continued pursuit of new treatments. We believe that the improvement in cardiac function that occurred during the two year follow up in patients with idiopathic myocarditis or idiopathic dilated cardiomyopathy treated with interferon- $\alpha$ or thymomodulin may have been the result of enhancement of immune function in patients who had a chronic myocardial viral infection.

Our results suggest that a combination of interferon- $\alpha$ and thymomodulin could improve function more than either drug given on its own-because of the early effects of interferon and the sustained effects of thymomodulin on immune function.

1 Kandolf R, Kirschner P, Ameis D, Canu A, Erdmann E, Schultheiss H-P, et al. Enteroviral heart disease: diagnosis by in situ hybridisation. In: Schultheiss HP, ed. New concepts in viral heart disease. Berlin: Springer-Verlag, 1988; cepts in vira.

2 Kandolf R, Ameis D, Kirschner P, Canu A, Hofschneider $\mathrm{PH}$. In situ detection of enteroviral genomes in myocardial cells by nucleic acid hybridization: an approach to the diagnosis of viral heart disease. Proc Natl Acad Sci USA 1987;84:6272-6.

3 Archard L, Freeke C, Richardson P, Meany B, Olsen E, Morgan-Capner $\mathrm{P}$, et al. Persistence of enterovirus RNA in dilated cardiomyopathy: a progression from myocarditis. In: Schultheiss HP, ed. New concepts in viral disease. Berlin: Springer-Verlag, 1988;349-62.

4 Bowles NE, Richardson PJ, Olsen EGJ, Archard LC Detection of Coxsackie-B-virus-specific RBA sequences in myocardial biopsy samples from patients with myocarditis and dilated cardiomyopathy. Lancet 1986;i:1120-3.

5 Weiss LM, Liu XF, Chang KL, Billingham ME. Detection of enteroviral RNA in idiopathic dilated cardiomyopathy and other human cardiac tissues. $\mathcal{F}$ Clin Invest 1992 90:156-9.

6 Klingel K, Hohenadl C, Canu A, Albrecht M, Seemann M Mall G, et al. Ongoing enterovirus-induced myocarditis is associated with persistent heart muscle infection: quantiative analysis of virus replication, tissue damage, an inflammation. Proc Natl Acad Sci USA 1992;89:314-8.

7 Aiuti F, Russo G, Carbonari M, Pontesilli O, Fiorilli M. A rational approach for the use of thymic hormones in viral infection and primary immunodeficiencies. In: Hesch $\mathrm{RD}$, ed. Peptide hormones as mediators in immunology and oncology. Serono Symposia Vol. 19. New York: Raven Press, 1985;185-9.

8 Oldstone MBA, Buchmeier MJ. Restricted expression of viral glycoprotein in cells of persistently infected mice. viral glycoprotein in cells
Nature 1982;300:360-62.

9 Kristensson K, Orvell C, Leestma J, Norrby E. Sendai virus infection in the brains of mice: distribution of viral antigens studied with monoclonal antibodies. F Infect Dis 1983;147:297-301.

10 Oldstone MBA, Fujinami RS, Lampert PW. Membrane and cytoplasmic changes in virus-infected cells induced and cytoplasmic changes in virus-infected cells induced by interactions of antiviral antibody

11 Figulla HR. Idiopathic dilated cardiomyopathy: current concepts in clinical research. In: Figulla HR, Kandolf R, McManus B, eds. Idiopathic dilated cardiomyopathy. Cellular and molecular mechanisms, clinical consequences. Berlin: Snd molecular mechanisms,

12 Aretz HT, Billingham ME, Edwards WD, Factor SM Fallon JT, Fenoglio J, et al. Myocarditis: a histological Fallon JT, Fenoglio Jj, et al. Myocarditis: a histological 1987;1:3-13.

13 Woodruff JF. Viral myocarditis: a review. Am f Pathol 1980;101:427-9. 
14 Maisch B, Trostel-Soeder R, Stechemesser E, Berg PA, Kochsiek K. Diagnostic relevance of humoral and cellmediated immune reactions in patients with acute viral myocarditis. Clin Exp Immunol 1982;48:533-4.

15 Disis ML, McDonald TL, Colombo JL, Kobayashi RH, Angle CR, Murray S. Circulating immune complexes in cystic fibrosis and their correlation to clinical parameters. Pediatr Res 1986;20:385-90. 16 Kay HD, Fagnani R, Bonnard GD. Cytotoxicity against
the K562 erythroleukemia cell line by human natural killer (NK) cells which do not bear free $F_{c}$ receptors for IgG. Int 7 Cancer 1979;21:141-50.

17 Hirsch RL, Johnson KP. The effects of long-term administration of recombinant Alpha-2 Interferon on lymphocyte subsets, proliferation, and suppressor cell function in multiple sclerosis. F Interferon Res 1986;6:171-7.

18 Mirić $M$, Brkić $S$, Vircburger $M$, Keserović N, Vučković $S$, Zdravkovic $\mathrm{M}$, et al. The effects of interferon-alpha administration on lymphocyte subsets and clinical findings in Coxsackie-virus B induced myocarditis. Iugoslav Physiol Pharmacol Acta 1988;24:257-63.

19 Mirić M, Brkić S, Pesić M, Keserović N, Igrutinović $L j$, Krušcic S, et al. Treatment of Coxsackie B induced Kruscic $\mathrm{S}$, et al. Treatment of Coxsacke B induced
myocarditis with thymus TFX thymomodulin and intermyocarditis with thymus TFX thymom

20 Maisch B, Herzum M, Schoenian U. Pathogenesis of dis- ease: humans. In: Banatvala JE, ed. Viral infections of the heart. London: Edward Arnold, 1993;138-75.

21 Huber SA. Viral myocarditis: a tale of two diseases. Lab Invest 1992;66:1-3.

22 Benczur M, Petranyi Gy, Varga M, Talas M, Motsy B, Foldes I, et al. Dysfunction of natural killer cells in multiple sclerosis-a possible pathogenetic factor. Clin Exp Immunol 1980;39:657-62.

23 Santoli D, Hall W, Kastrukoff L, Lisak RP, Perussia B, Trinchieri $\mathrm{G}$, et al. Cytotoxic activity and interferon production by lymphocytes from patients with multiple sclerosis. F Immunol 1981;126:1274.

24 Mason JW, O'Connell JB, Herskowitz A, Rose NR, McManus BM, Billingham ME, et al. A clinical trial of immunosuppressive therapy for myocarditis. $N$ Engl f Med 1995;333:269-75.

25 Cohen MC, Muberman MS, Nesto RW. Recombinant alpha 2 interferon-related cardiomyopathy. $\mathrm{Am} \mathcal{F} \mathrm{Med}$ 1988;85:549-51.

26 Deyton LR, Walker RE, Kovacs JA, Herpin B, Parker M Masur $\mathrm{H}$, et al. Reversible cardiac dysfunction associated
with interferon alpha therapy in AIDS patients with waposi's sarcoma. N Engl f Med 1989;321:1246-9.

27 Sonnenblick M, Rosenmann D, Rosin A. Reversible cardiomyopathy induced by interferon. Br Med $\mathcal{f} 1990$; 300:1174-5. 